\title{
Regeneration of paint sludge and reuse in cement concrete
}

\author{
Enqi Feng ${ }^{l}$, Jitao Sun $^{2}$, and Liming Feng ${ }^{3, *}$ \\ ${ }^{1}$ Xiamen University, College of Chemistry and Chemical Engineering, 361005Ximen,Fujian, China \\ ${ }^{2}$ Tai an LEBANG Environmental Technology Co., Ltd, 271208Tai' an,Shandong, China \\ ${ }^{3}$ Shandong Jianzhu University, School of Materials Science and Engineering, 250101 Ji'nan,Shandong, China
}

\begin{abstract}
Paint Sludge (PS) is a hazardous waste. Inappropriate disposal of PS might be harmful to public health and the environment. Various size of Paint Sludge Solid Powder (PSSP) particles have been produced by automatic processing equipment via dewatering, crushing, screening removing Volatile Organic Compounds (VOCs), and etc. Meanwhile, the test results show that PSSP is not a hazardous waste. Both flexural and compressive strength are increased by adding PSSP of polyurethane to cement concrete at a level of below $10 \%$ of cement weight. However, the strength has a significant reduction at a level of above $15 \%$ of cement weight. The reason for the increase of strength is probably due to a slow coagulation and copolymerization of PSSP and cement. The reduction is likely due to the self-reunion of PSSP.
\end{abstract}

\section{Introduction}

The raw PS produced by automotive industry by using Sediment Scraper usually contains $75-90 \mathrm{wt} . \%$ of water and $10 \mathrm{wt} . \%$ of volatile organic compounds(VOCs). Therefore, removing water and VOCs from the raw PS is very important for recycling PS. However, it is difficult to reduce the water below $40 \mathrm{wt} . \%$ of PS by mechanical dehydration, besides, the dewatered PS is easy to form a soft lump quickly. This also increases the difficulty of recycling. E. M. James designed a Vacuum Filtration System for dewatering PS [1]. It could enhance dewatering in vacuum chamber by using negative pressure. Then, remove residual water by using hot pressurized air. R. Elangovan also designed PS recovery and reuse converting machine [2]. First, the water and solvent in raw PS turn into steam (vapor and VOCs) by heating the PS. Then, the mixed steam was collected through cooling unit, collection unit, wet scrubber unit, and ect. This machine could recover $34 \%$ of reusable solvent, $48 \%$ of stabilized solid residue and $18 \%$ of water. Although these equipment can effectively dewater the PS, they couldn't dewater enough if there was no crushing device. Therefore, the reprocessed PS is difficult to reuse directly. Recently, a comprehensive processing and utilization equipment for PS was designed by LEBANG Co., Ltd in Tai'an, China [3]. All processing units such as dewatering, drying, crushing, and etc. are integrated together. So it is easy to produce PSSP with 50-1000 mesh and less than $2 \%$ of water. Especially, the treating process will not cause environmental pollution because it has a treatment system for waste water, waste gases, and dedusting.

Recycling and reusing the PS has been an important topic in recent years. The primary study focuses on construction and road pavement materials. Lightweight construction materials have been obtained using PS of acrylic resin as a partial replacement for sand in cement concrete [4]. The results have demonstrated that these materials can be used in residential construction. Furthermore, as modifier replaced partial asphalt, satisfactory results have been achieved in road pavements $[5,6]$.

In this study, we produced PSSP of polyurethane which was regenerated from the automatic equipment for recycling PS made by LEBANG Co., Ltd. The purpose is to add PSSP of polyurethane into the concrete product as a filler and investigate the effects of different additives and percentages of PSSP on flexural and compressive strength.

\section{Materials and Methods}

Materials for this study include cement, sand, water, and regenerated PSSP. The raw PS was provided from automotive industries of SINOTRUK Co., Ltd in Ji'nan, China. The cement is the commercially available type P.O32.5 (GB175-2007). Sand was acquired from an unknown source.

The experiments include two steps. First, the raw PS was processed into PSSP with 200 mesh size. Then, this PSSP was mixed with cement, water and sand in certain proportions. The standard size of molds was $40 \mathrm{~mm} \times 40 \mathrm{~mm} \times 160 \mathrm{~mm}$ cubes. The preliminary assessment for all specimens was performed at 7 days of aging .

\subsection{Preparation of PSSP}

According to PS processing flow chart in Figure1, the raw PS of polyurethane (Figure2) was regenerated into

\footnotetext{
* Corresponding author: flm@sdjzu.edu.cn
} 


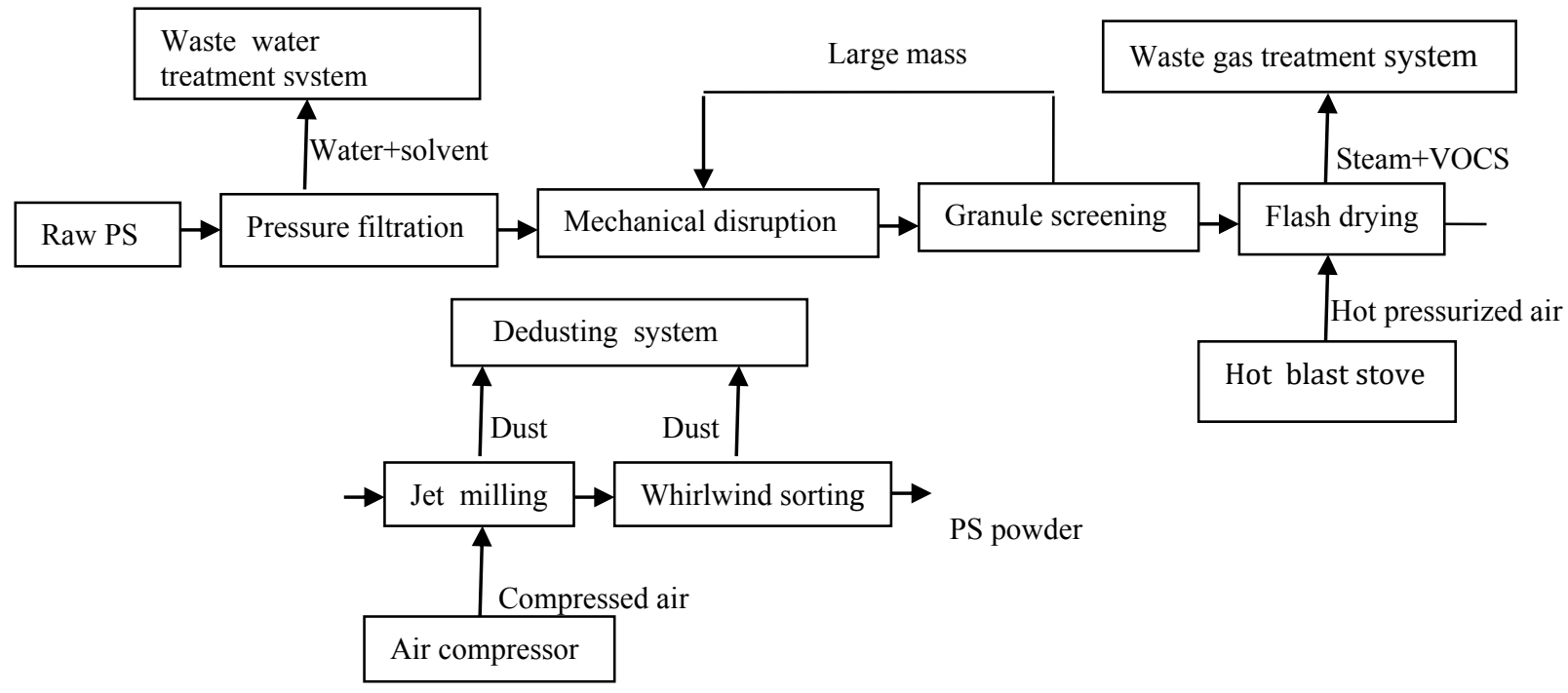

Fig. 1. PS process flow chart.

PSSP with 200 mesh (Figure3). The chemical composition and leaching toxicity before and after treatment were shown in Table1.

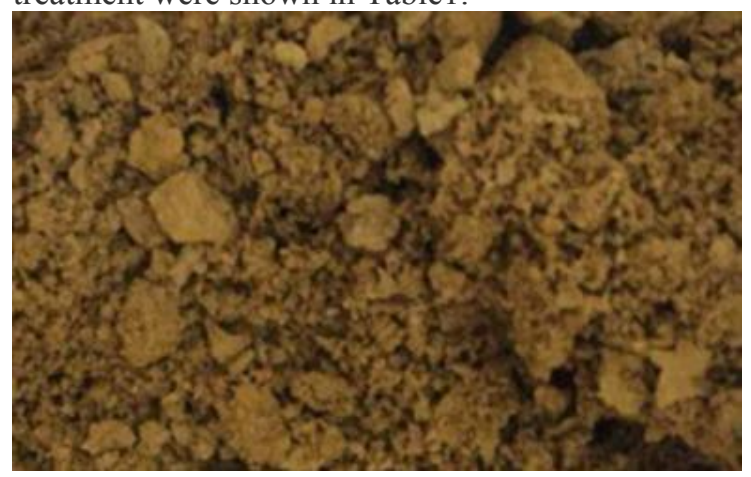

Fig.2 .The raw PS.

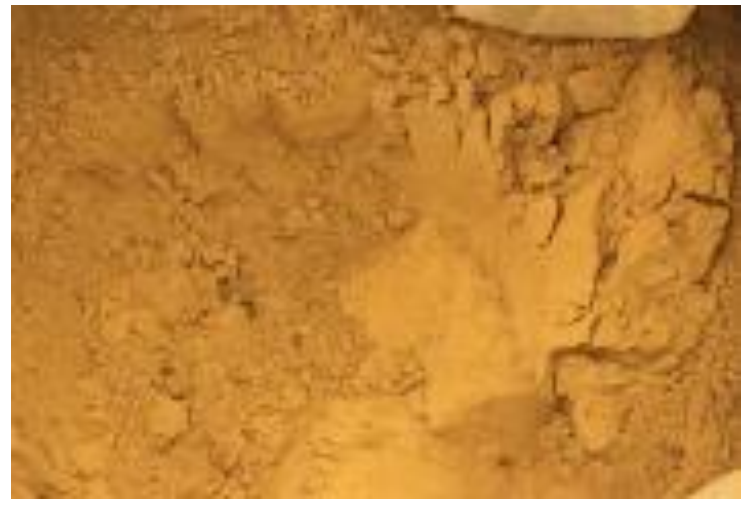

Fig.3. PSSP with 200 mesh.

\subsection{Preparation of the PSSP-concrete specimens}

According to the test of water absorption rate of PSSP and method of cement mortar test in ISO679:1989, the water was increased by one third of PSSP accordingly.

This study investigated the effects of additives and PS content on mechanical properties of PSSP-concrete.
Bubbles and interfaces may be created when PSSP is mixed with concrete because the PSSP is mainly composed of polymer resin and pigment. Therefore, it is necessary to modify it using additives such as surfactants (sodium polyphosphate), defoamers (DF460) at a level $2 \%$ and $2.5 \%$ of total water, respectively. The exact compositions with different additives are shown in Table2. Furthermore, the compositions with same additives, PSSP contents of 5,10,15,20wt.\% of cement are shown in Table 3.

\subsection{Mechanical Properties}

Flexural and compressive tests were performed by using Full-automatic cement pressure testing machine (DYH300B ) whose precision is grade1 and maximum stroke is $100 \mathrm{~mm}$.

\section{Results and Discussion}

\subsection{Results of PSSP regeneration treatment}

According to the results in Table 1, the regenerated PSSP is no longer hazardous waste because leaching toxicity is far lower than the national standard values of hazardous waste[7]. In addition, the water and VOCs level of PS are significantly decreased. The data indicates that water content from 31.5 to $1.7 \mathrm{wt} . \%$ with the removal efficiency at $94.6 \%$.

\subsection{Effects of additives on strength of PSSP- concrete}

Figure 4 and Figure 5 show the results of flexural and compressive test for PSSP-concrete respectively. As can be seen, when PSSP accounts for 5\% of cement weight, flexural and compressive strength of specimens are increased by $5.76 \%, 12.46 \%$ with single surfactant, $3.36 \%, 12.69 \%$ with single defoamer, $1.4 \%, 16.8 \%$ with 
both surfactant and defoamer, respectively. In addition, when PSSP accounts for $10 \%$ of cement weight, flexural strength is decreased by $8.6 \%, 2.16 \%$, compressive strength is increased by $10.8 \%, 14.8 \%$ with single surfactant and defoamer. As expected, flexural and compressive strength of specimens are increased by

Table 1.Changes in chemical composition of PS before and after treatment.

\begin{tabular}{|c|c|c|c|c|}
\hline Chemical composition & Text method & $\begin{array}{c}\text { Level in before } \\
\text { treatment }\end{array}$ & $\begin{array}{c}\text { Level in after } \\
\text { treatment }\end{array}$ & $\begin{array}{l}\text { National } \\
\text { standard }\end{array}$ \\
\hline Water weight (\%) & $\mathrm{CJ} / \mathrm{T} 221$ & 31.5 & 1.7 & \\
\hline Petroleum solvent $(\mathrm{mg} / \mathrm{kg})$ & GB5085.6 & - & $1.54 \times 10^{3}$ & \\
\hline Isophorone $(\mathrm{mg} / \mathrm{kg})$ & GB5085.3 & - & $<5$ & \\
\hline acetone $(\mathrm{mg} / \mathrm{kg})$ & GB5085.3 & 588 & $<20$ & \\
\hline benzene $(\mathrm{mg} / \mathrm{kg})$ & GB5085.3 & $<0.05$ & $<0.05$ & \\
\hline toluene $(\mathrm{mg} / \mathrm{kg})$ & GB5085.3 & $2.92 \times 10^{3}$ & 1.33 & \\
\hline p-xylene $(\mathrm{mg} / \mathrm{kg})$ & GB5085.3 & $1.29 \times 10^{4}$ & 11.0 & \\
\hline styrol $(\mathrm{mg} / \mathrm{kg})$ & GB5085.3 & 12.4 & 0.17 & \\
\hline o-xylene(mg/kg) & GB5085.3 & $7.05 \times 10^{3}$ & 8.52 & \\
\hline chlorobenzene(mg/kg) & GB5085.3 & $<0.05$ & 0.29 & \\
\hline 1,3-dichlorobenzene $(\mathrm{mg} / \mathrm{kg})$ & GB5085.3 & $<0.05$ & $<0.05$ & \\
\hline 1,4-dichlorobenzene $(\mathrm{mg} / \mathrm{kg})$ & GB5085.3 & $<0.05$ & $<0.05$ & \\
\hline 1,2-dichlorobenzene $(\mathrm{mg} / \mathrm{kg})$ & GB5085.3 & $<0.05$ & $<0.05$ & \\
\hline 1,2,4-trichlorobenzene $(\mathrm{mg} / \mathrm{kg})$ & GB5085.3 & $<0.05$ & $<0.05$ & \\
\hline 1,2,3-trichlorobenzene $(\mathrm{mg} / \mathrm{kg})$ & GB5085.3 & $<0.05$ & $<0.05$ & \\
\hline $\mathrm{PO}(\mathrm{mg} / \mathrm{kg})$ & GB5085.3 & $<25$ & $<25$ & \\
\hline MTBE(mg/kg) & GB5085.3 & $<0.5$ & $<0.5$ & \\
\hline Epoxyethane(mg/kg) & GB5085.3 & $<10$ & $<10$ & \\
\hline Epichlorohydrin $(\mathrm{mg} / \mathrm{kg})$ & GB5085.3 & $<50$ & $<50$ & \\
\hline $\mathrm{TBA}(\mathrm{mg} / \mathrm{kg})$ & GB5085.3 & $<10$ & $<10$ & \\
\hline $\mathrm{ETO}(\mathrm{mg} / \mathrm{kg})$ & GB5085.3 & $<1$ & $<1$ & \\
\hline n-butyl alcohol(mg/kg) & GB5085.3 & $<10$ & $<10$ & \\
\hline 2-butanol(mg/kg) & GB5085.3 & $<50$ & $<50$ & \\
\hline $\operatorname{MEK}(\mathrm{mg} / \mathrm{kg})$ & GB5085.3 & $<20$ & $<20$ & \\
\hline $\mathrm{MIBK}(\mathrm{mg} / \mathrm{kg})$ & GB5085.3 & $<20$ & $<20$ & \\
\hline Isobutanol(mg/kg) & GB5085.3 & $<50$ & $<50$ & \\
\hline Acrolein $(\mathrm{mg} / \mathrm{kg})$ & GB5085.3 & $<10$ & $<10$ & \\
\hline 2-nitropropane(mg/kg) & GB5085.3 & $<10$ & $<10$ & \\
\hline Acetonitrile(mg/kg) & GB5085.3 & $<5$ & $<5$ & \\
\hline$\delta$-chlorotoluene $(\mathrm{mg} / \mathrm{kg})$ & GB5085.3 & $<1$ & $<1$ & \\
\hline EAC & USEPA 8260C & $<0.1$ & & \\
\hline n-butyl acetate & USEPA $8260 \mathrm{C}$ & 61.5 & & \\
\hline Total vocs $(\mathrm{mg} / \mathrm{kg})$ & GB5085.3 & & $<6.6$ & \\
\hline \multicolumn{5}{|c|}{ leaching toxicity } \\
\hline $\mathrm{Ba}(\mathrm{mg} / \mathrm{L})$ & GB5085.3 & & 0.06 & $\leq 100$ \\
\hline $\mathrm{Cd}(\mathrm{mg} / \mathrm{L})$ & GB5085.3 & & $<0.001$ & $\leq 1$ \\
\hline Total Cr(mg/L) & GB5085.3 & & 0.07 & $\leq 15$ \\
\hline $\mathrm{Hg}(\mathrm{mg} / \mathrm{L})$ & GB5085.3 & & $<0.005$ & $\leq 0.1$ \\
\hline $\mathrm{Pb}(\mathrm{mg} / \mathrm{L})$ & GB5085.3 & & $<0.01$ & $\leq 5$ \\
\hline $\mathrm{Zn}(\mathrm{mg} / \mathrm{L})$ & GB5085.3 & & 1.35 & $\leq 100$ \\
\hline $\mathrm{As}(\mathrm{mg} / \mathrm{L})$ & GB5085.3 & & $<0.05$ & $\leq 5$ \\
\hline $\mathrm{Cr}^{6+}(\mathrm{mg} / \mathrm{L})$ & GB/T 15555.4 & & 0.067 & $\leq 5$ \\
\hline $\mathrm{DOP}(\mathrm{mg} / \mathrm{L})$ & GB5085.3 & & $<0.0025$ & $\leq 3$ \\
\hline benzene $(\mathrm{mg} / \mathrm{L})$ & GB5085.3 & & $<0.0500$ & $\leq 1$ \\
\hline toluene $(\mathrm{mg} / \mathrm{L})$ & GB5085.3 & & $<0.0500$ & $\leq 1$ \\
\hline xylene $(\mathrm{mg} / \mathrm{L})$ & GB5085.3 & & $<0.100$ & $\leq 4$ \\
\hline
\end{tabular}


$1.4 \% 、 16.8 \%$ with both surfactant and defoamer. Unfortunately, both flexural and compressive strength of specimens declined with increasing PSSP to top $15 \%$ of cement weight in either group. It is evident that surfactant and defoamer have similar effect when PSSP content at 5\%. However, the defoamer had more significant effect when PSSP content is more than $10 \%$. This may be because sodium polyphosphate not only

Table 2. Compositions with different additives.

\begin{tabular}{llllllccc}
\hline Series & $\begin{array}{l}\text { Cement } \\
(\mathrm{g})\end{array}$ & $\begin{array}{l}\text { Sand } \\
(\mathrm{g})\end{array}$ & $\begin{array}{l}\text { PSSP } \\
(\mathrm{g})\end{array}$ & $\begin{array}{l}\text { Water } \\
(\mathrm{ml})\end{array}$ & $\begin{array}{l}\text { Surfactants } \\
(\mathrm{g})\end{array}$ & $\begin{array}{c}\text { Defoamer } \\
(\mathrm{ml})\end{array}$ & $\begin{array}{l}\text { Flexural } \\
(\mathrm{MPa})\end{array}$ & $\begin{array}{c}\text { Compressive } \\
(\mathrm{MPa})\end{array}$ \\
\hline 1 & 450 & 1350 & 0 & 225 & & & 4.17 & 30.10 \\
2 & 450 & 1350 & 22.5 & 232.5 & 0.465 & & 4.41 & 33.85 \\
3 & 450 & 1350 & 22.5 & 232.5 & & 0.57 & 4.31 & 33.92 \\
4 & 450 & 1350 & 22.5 & 232.5 & 0.465 & 0.57 & 4.30 & 35.13 \\
5 & 450 & 1350 & 45 & 240 & 0.48 & & 3.81 & 33.36 \\
6 & 450 & 1350 & 45 & 240 & & 0.6 & 4.08 & 34.55 \\
7 & 450 & 1350 & 45 & 240 & 0.48 & 0.6 & 4.23 & 35.16 \\
8 & 450 & 1350 & 67.5 & 247.5 & 0.495 & & 3.11 & 28.28 \\
9 & 450 & 1350 & 67.5 & 247.5 & & 0.619 & 3.86 & 31.60 \\
10 & 450 & 1350 & 67.5 & 247.5 & 0.495 & 0.619 & 3.76 & 34.46 \\
\hline
\end{tabular}

Table 3. Compositions with the same additives, different percentages of PSSP.

\begin{tabular}{lccclllll}
\hline Series & $\begin{array}{c}\text { Cement } \\
(\mathrm{g})\end{array}$ & $\begin{array}{c}\text { Sand } \\
(\mathrm{g})\end{array}$ & $\begin{array}{c}\text { PSSP } \\
(\mathrm{g})\end{array}$ & $\begin{array}{l}\text { Water } \\
(\mathrm{ml})\end{array}$ & $\begin{array}{c}\text { Surfactants } \\
(\mathrm{g})\end{array}$ & $\begin{array}{c}\text { Defoamer } \\
(\mathrm{ml})\end{array}$ & $\begin{array}{l}\text { Flexural } \\
(\mathrm{MPa})\end{array}$ & $\begin{array}{l}\text { Compressive } \\
(\mathrm{MPa})\end{array}$ \\
\hline 1 & 450 & 1350 & 0 & 225 & & & 4.17 & 35.10 \\
2 & 450 & 1350 & 22.5 & 232.5 & 0.465 & 0.57 & 4.30 & 35.13 \\
3 & 450 & 1350 & 45 & 240 & 0.48 & 0.6 & 4.23 & 35.16 \\
4 & 450 & 1350 & 67.5 & 247.5 & 0.495 & 0.619 & 3.76 & 34.46 \\
5 & 450 & 1350 & 90 & 255 & 0.51 & 0.64 & 3.50 & 27.44 \\
\hline
\end{tabular}

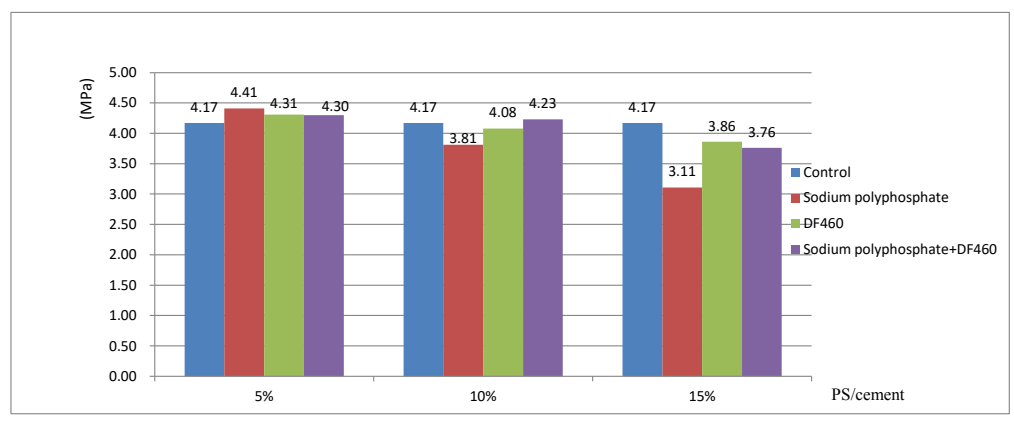

Fig.4. Effects of different additives on flexural strength. 


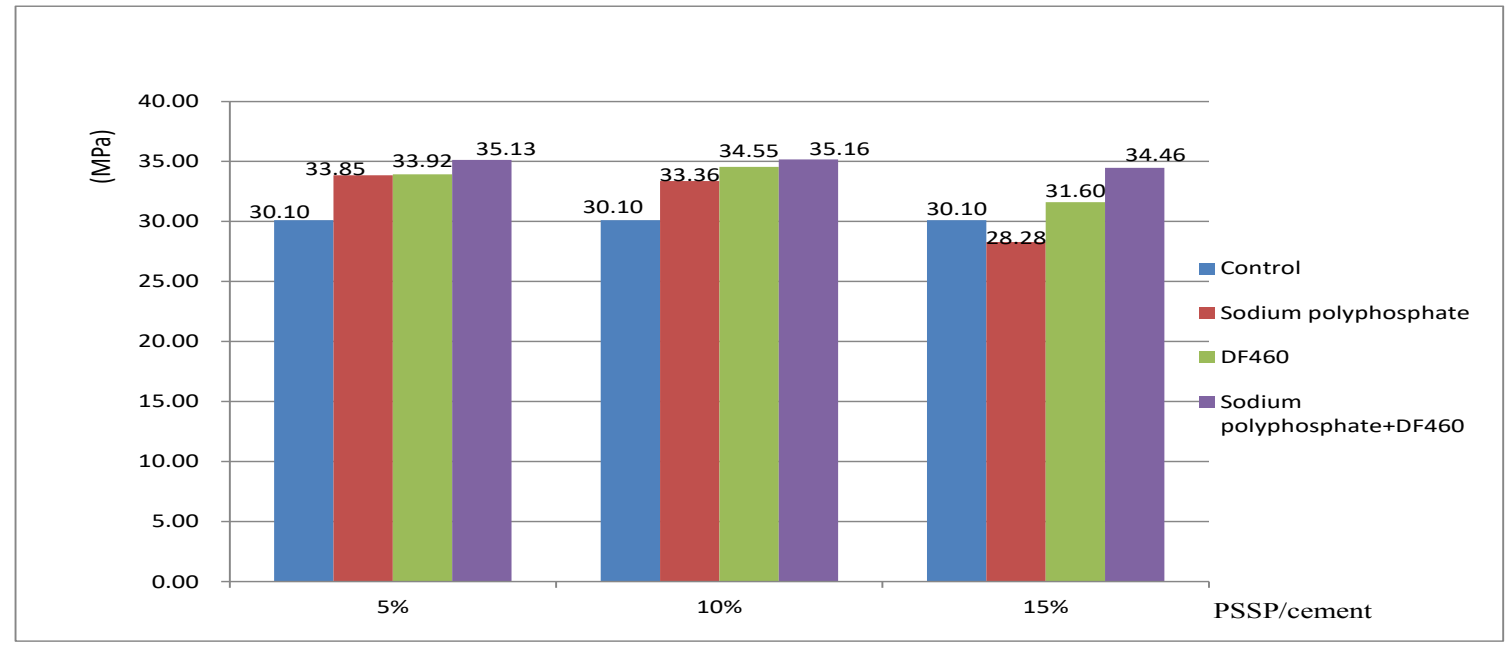

Fig. 5. Effects of different additives on compressive strength.

increases wettability but also forms complex compound with $\mathrm{Ca}^{2+}, \mathrm{Mg}^{2+}$ in PSSP and cement as a bridge. Moreover, DF460 is mainly to eliminate bubbles. Usually, the PSSP contains small amount of residual flocculant, more bubbles come into mortar mixture with an increase of PSSP content. Apparently, the bubbles become the main factors. Using sodium polyphosphate and DF460 together had synergistic effect to increase strength of specimens.

\subsection{Effects of PSSP Content on Strength of PSSP-Concrete}

The strength tests have been performed to determine the effects of PSSP content using sodium polyphosphate and DF460 together. Figure 6 shows the result of strength test for PSSP-concrete. As seen in figures, when PSSP content below $10 \%$, the flexural and compressive strength have been greatly improved. In here, the maximum compressive strength increased by $16.7 \%$ compared with the control sample. However, the strength began to decline when the PSSP reaches to $15 \%$. Unfortunately, the strength is far lower than control sample when PSSP reaches to $20 \%$. These regularities are probably due to small amount of residual isocyanate and hydroxyl in PSSP can cause copolymerization with the hydroxyl in cement. So the degree of cross-linking is improved. In the mean time, PSSP may alleviate hydration of cement and reduce stress between sand and cement as filler to increase strength. Of course, PSSP can be agglomerated when the dosage is too high, which could increase the interface between powders and cement paste to decrease strength.

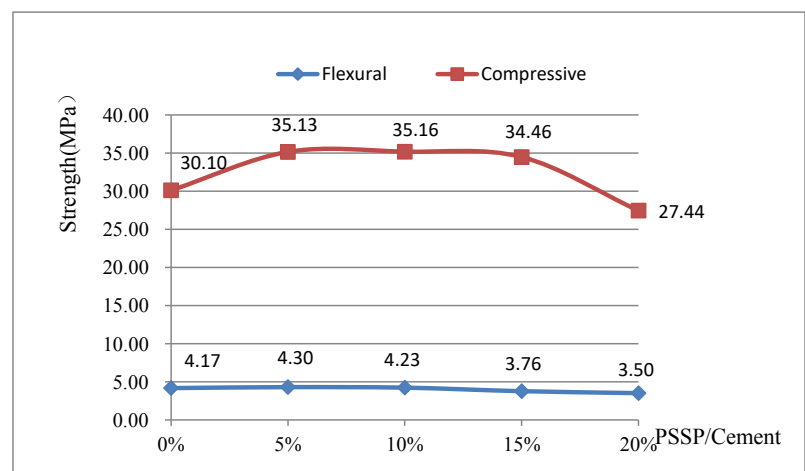

Fig. 6. Relationships between the strength and wt.\% PSSP.

\section{Conclusion}

In this study, we focused on the regeneration of PS and reuse in cement concrete. We produced nontoxic PSSP. Based on the results from PSSM-concrete, changes of mechanical property have been observed.

PSSP with different particle size range can be obtained via high efficiency dehydration, crushing and screening by using comprehensive processing and utilization equipment for PS. More importantly, the PSSP is no longer hazardous waste.

The flexural and compressive strength of specimens are improved by adding PSSP below $10 \%$ of cement content in concrete. The flexural and compressive strength of specimens are significantly declined by adding PSSP above $15 \%$ of cement content in concrete.

\section{References}

1. E. M . James. US. pat. No.20040031739A1 (2004)

2. R.Elangovan, TAB, BARATHI. WO. pat. No. 2014037954A1 (2014)

3. L. M. Feng, F. Q. He, et al. CHN. pat.No.2017106782839(2017)

4. H.Avci, H.Ghorbanpoor, etal. J. Environ. Chem. Eng. 5(1),861-869 (2017) 
5. D. Dalmazzo, A .Vercelli ,E.Santagata ,B. Ruffino, et al. Mater. Struct. 50 (1),1-14(2017)

6. M. C. Zanetti, B. Ruffino, et al. CEST2017, Rhodes, Greece.

7. GB5085.3-2007, SEPA and AQSIQ, Beijing , China 